\title{
Colonização e Conquista: um projeto para os sertões fluminenses (1790-1800)
}

\section{Marina Monteiro Machado}

\begin{abstract}
Resumo: A ocupação dos sertões do Rio de Janeiro, na passagem do século XVIII para o século XIX, viveu um período de intensos conflitos e negociações, em um processo que envolveu agentes diversos, entre os quais: sesmeiros, posseiros, fazendeiros, grupos indígenas e agentes da Coroa Portuguesa. Uma realidade cotidiana que misturava interesses específicos e projetos distintos. No presente trabalho, pretende-se analisar o projeto do fazendeiro José Rodrigues da Cruz para o aldeamento dos índios de Valença, no interior do Rio de Janeiro. Ainda que não exista um projeto formal, a análise de correspondências do fazendeiro nos permite analisar uma proposta específica, para a colonização dos grupos indígenas e para a consequente expansão da fronteira da colonização.
\end{abstract}

Palavras-Chave: Fronteira; Aldeamentos; Terras.

\begin{abstract}
The occupation of the sertões of Rio de Janeiro, in the passage from the eighteenth to the nineteenth century, was a period of intense conflict and negotiations in a process involving several agents, among them: sesmeiros, squatters, farmers, indigenous groups and agents the Portuguese government. An everyday reality that mixed specific interests and distinct projects. The present study analyzes the project of the farmer José Rodrigues da Cruz to the Indian civilization of Valencia, within the Rio de Janeiro. Although there is no formal project, the correspondence analysis of the farmer, allows us to analyze a specific proposal for settlement of indigenous groups and the consequent expansion of the frontier.
\end{abstract}

Keywords: Frontier; Aldeamentos; Lands.

[...] promover a civilização do gentio bravo que infestava o sertão do Paraíba com grande dano aos moradores. ${ }^{1}$

No interior da capitania do Rio de Janeiro, no fluido espaço da fronteira, no qual colonizadores, grupos indígenas, religiosos e tantos outros agentes se encontram, construindo relações negociadas na sucessão dos dias, o fazendeiro José Rodrigues da Cruz recebe uma correspondência vinda da Corte. Interessava diretamente ao governo lusobrasileiro, que se fazia representar na carta redigida pelo ministro Dom Rodrigo de Souza

\footnotetext{
* Este artigo é parte de um trabalho mais amplo sobre a história do Aldeamento de Nossa Senhora da Glória de Valença e sobre a ocupação do Médio Paraíba, apresentado como tese de doutoramento defendida em dezembro de 2010. Por meio do Programa de Pós-graduação da Universidade Federal Fluminense, o trabalho foi financiado por bolsa concedida pelo CNPq e publicado no livro MACHADO, M. M. (2012) Entre Fronteiras: posses e terras indígenas nos sertões (Rio de Janeiro, 1790-1824), São Paulo; Guarapuava; Niterói: Editora Horizonte; Editora UNICENTRO; Editora da UFF.

${ }^{1}$ Ofício de João Pacheco... ao vice-rei, 12 ago. 1797.
} 
Coutinho $^{2}$, o trabalho que estava sendo desenvolvido com os grupos indígenas locais, no escopo do interesse na expansão da fronteira fluminense. Ao receber carta enviada por tão nobre remetente, o fazendeiro procura responder às questões levantadas e empenha-se em estabelecer aliança com o governo. Passa a constituir, assim, um elemento-chave, um intermediário entre os dois mundos distintos que se misturam no processo de colonização dos sertões, e é a partir dos dados presentes na tal troca de correspondência que damos início à presente análise, que pretende refletir sobre a atuação de agentes no espaço da fronteira, considerando a interseção dos interesses distintos e projetos de colonização para os grupos indígenas na construção desta nova realidade, o mundo colonial.

O fazendeiro inicia sua resposta reconhecendo:

A honra e a mercê que Sua Majestade foi servida fazer-me de aprovar meu comportamento passado e de confiar que para o futuro eu me conduza de modo, que haja merecer o seu real agrado é para mim um prêmio muito superior ao meu merecimento. ${ }^{3}$

O ministro havia entrado em contato com o fazendeiro por meio de uma correspondência escrita, após ter conhecimento de que o primeiro vinha estabelecendo contato e convívio com os grupos indígenas do sertão fluminense, na região do Médio Paraíba, grupos até então tidos como selvagens, não domesticados e de difícil convivência. Ao escrever para o fazendeiro, Dom Rodrigo lista algumas questões que o vinham incomodando e que pretendia resolver para seguir adiante com seus planos para o Império luso-brasileiro. Solicitava então o ministro a opinião e o auxílio do fazendeiro para solucionar quatro questões, a saber: a navegação do rio Paraíba do Sul, as possibilidades de cortes de madeira, a efetiva ocupação das terras por colonizadores e o controle dos índios bravos. De uma forma genérica, podemos resumir os pontos elencados em apenas uma questão fundamental que vinha a ser uma forma de tornar aquela região $e$ consequentemente aqueles sertões rentáveis para o império luso-brasileiro.

Cabe destacar que a correspondência do ministro, assim como suas respectivas questões, não foi encaminhada apenas ao fazendeiro. Como era de praxe, Souza Coutinho enviou as mesmas solicitações a diferentes interlocutores, mas desde o início nos foi bastante curioso o desenvolvimento do diálogo e da parceria de trabalho suscitados entre os dois personagens em tela; a nosso ver, era resultado de uma interseção não apenas de interesses, mas sobretudo de uma visão, uma concepção em prol da construção de um projeto comum.

Em sua resposta ao ministro, o fazendeiro deixa claro seu interesse em continuar o trabalho, que já vinha sendo realizado, agora com o aval da Coroa e, buscando dar conta

\footnotetext{
${ }^{2}$ Sobre o ministro Dom Rodrigo de Souza Coutinho ver: MACHADO, M. M. Entre Fronteiras: terras indígenas nos sertões fluminenses (1790-1824). Niterói, 2010. Tese (Doutorado em História) - PPG História, Universidade Federal Fluminense; SANTOS, Nívia P. C. Dom Rodrigo de Souza Coutinho: pensamento e ação políticoadministrativa no império português (1778-1812). Dissertação (Mestrado em História) - PPGH/UFF. Niterói, 2002.

${ }^{3}$ Carta de José Rodrigues da Cruz em resposta a D. Rodrigo... 1. out. 1799.
} 
dos quatro itens arrolados na carta do ministro, descreve minuciosamente sua relação com os grupos indígenas da região. Afirma a dificuldade de navegação dos rios, por conta da quantidade de quedas d'água e cachoeiras, características da região de serra; para a ocupação das terras sugere a necessidade de concessão de sesmarias, salientando que se deve observar a lei e garantir o seu cultivo; para o corte de madeiras, o fazendeiro sugeria o aproveitamento da mão de obra indígena, que seria possível a partir de um projeto voltado para a pacificação dos índios, que afirmava inclusive já ter iniciado. José Rodrigues da Cruz apresenta ideias próprias para se obter sucesso na pacificação dos grupos indígenas, garantindo o controle da situação e promovendo a ocupação europeia das terras; de uma só vez, o fazendeiro parecia propor soluções que atendiam como um todo aos interesses da Coroa para garantir o desenvolvimento da região.

Tenho a satisfação de concorrer para o serviço da Igreja, e do Estado na civilização dos Índios ao longo do dito rio [Paraíba do Sul]: os quaes desde o ano de 1780 principiaram a ter comigo, e continuarão até o presente uma pacífica e amigável correspondência. ${ }^{4}$

A relação construída vinha sendo tecida há mais de uma década e a mencionada aproximação teria sido possibilitada pelas duas partes. O fazendeiro afirmava que teria partido dos próprios índios a iniciativa de visitar a fazenda e, após esse episódio, Rodrigues da Cruz diz ter orientado todos os seus subordinados, feitores e escravos a receberem os grupos nativos como amigos, dando-lhes de graça todo o mantimento que pedissem e avisando ao proprietário, para que ele pudesse tomar providências em prol da aproximação e da convivência dos grupos.

Ao longo de suas linhas, o fazendeiro descreve ao ministro e aos demais leitores uma realidade de receptividade e cortesia:

[...] Tive o aviso de estarem os Índios na Fazenda do Pao-Grande, aonde eu residia; fui sair-Ihes ao encontro, com minha gente armada por cautela, mas logo que os avistei mandei os meus que depusessem as armas. O Cacique [...] mandou o mesmo aos seus e veio abraçar-me: eu o tratei com a mesma cortesia. [...] os fiz conduzir a minha casa [...] e para lhes tirar todo motivo de suspeita e desconfiança, fiz aparecer ali toda a minha família; eles se portarão com sinais de respeito e gratidão, oferecendo aos meus meninos os papagaios que traziam [...] eu os persuadi como pude, que estimaria que eles voltassem muitas vezes a minha fazenda e que achariam sempre em mim o mesmo agasalho; eles assim o prometeram fazer. Nenhum de nós tem faltado ao prometido, eles vindo todos os anos [...] e eu os tratando sempre com a mesma liberdade e boa fé. ${ }^{5}$

As palavras do fazendeiro apresentam uma realidade cordial e pacífica, decorrente das trocas realizadas, que envolviam produtos e interesses de ambos os lados. Não podemos, entretanto, nos levar por vocábulos que estavam divulgando ao governo o

\footnotetext{
${ }^{4}$ Idem.

${ }^{5}$ Carta de José Rodrigues da Cruz em resposta a D. Rodrigo... 1.o out. 1799.
} 
trabalho realizado, e que de certo buscariam passar a melhor imagem possível. Atentemos para o fato de o fazendeiro deixar clara sua preocupação em "persuadir" os índios a retornar outras vezes, reconhecendo a possibilidade de uma aliança com aquela fazenda e seus moradores.

José Rodrigues da Cruz, até então um anônimo fazendeiro e administrador de fazendas no interior fluminense, começava a despontar como uma figura central na história aqui analisada, colocando-se à disposição da Coroa e dos grupos indígenas, estabelecendo novas relações, além de cultivar as já existentes, sem que se possa aqui afirmar se já vislumbrava, ou não, que tais relações lhe seriam vantajosas, assim como a forma e a intensidade dessas possíveis vantagens.

Iniciava-se, com essas correspondências, um diálogo que atravessava o Atlântico e aproximava interesses e esforços presentes nos dois lados desse oceano, em favor de uma única ação: expandir as fronteiras da capitania do Rio de Janeiro. A carta enviada pelo fazendeiro recebe como resposta outra correspondência de Dom Rodrigo de Souza Coutinho, em apenas cinco meses. O ministro português afirma ter ele próprio levado ao príncipe regente a carta de José Rodrigues da Cruz, tendo sido recebida com uma "justa satisfação ao ponto de se dignar o mesmo augusto senhor de mandar remeter uma cópia d'ela ao vice-rei do Estado do Brasil". ${ }^{6}$ Seu intuito era o de garantir ao fazendeiro as condições possíveis e necessárias para que este continuasse seu movimento de aproximação com os grupos indígenas, em vista da pacificação desses grupos, que tantos problemas já haviam causado para a colonização da região.

Seguindo ainda com os planos de efetiva ocupação das terras a partir da expansão da fronteira em pauta, o príncipe regente, na esperança de aumentar "a civilização e trato dos índios e a sua conversão às luzes evangélicas" ${ }^{7}$, menciona a possibilidade de conceder terras por meio de sesmarias, assim estimulando "a povoação das margens superiores do rio Paraíba". ${ }^{8}$ Decisão essa que se apresenta em total consonância com as sugestões anteriormente apresentadas por Rodrigues da Cruz, que podem ainda ser lidas como uma abertura oficial dessa parte da fronteira fluminense, pelo governo luso-brasileiro. Não estamos aqui defendendo que as ações do príncipe regente seguiam as sugestões do fazendeiro, mas reconhecendo, sim, que ambos estavam de acordo com diretrizes similares e concordando em seus projetos de colonização dos grupos indígenas e de expansão da fronteira fluminense. Abertura determinada pelo próprio príncipe regente, que decide conceder as terras a sesmeiros, estimulando "a povoação", e consequentemente ignorando outra ocupação já existente, desconsiderando que essas terras eram povoadas por outros grupos, que não os colonizadores, e estes por sua vez estabeleciam suas próprias relações com o território ocupado.

No mesmo contexto (início de março de 1800) em que escreve para José Rodrigues da Cruz, no interior de Valença, Dom Rodrigo redige um aviso ao vice-rei do Brasil, Dom

\footnotetext{
${ }^{6}$ Ofício de D. Rodrigo de Souza Coutinho a José Rodrigues da Cruz, 7 mar. 1800.

${ }^{7}$ Ofício de D. Rodrigo... a Rodrigues da Cruz, 7 mar. 1800.

${ }^{8}$ Ofício de D. Rodrigo... a Rodrigues da Cruz, 7 mar. 1800.
} 
José de Castro. O ministro procura dar continuidade à intervenção pública no que tange aos índios de Valença, investindo em um projeto de aldeamento, dando prosseguimento aos acordos que foram firmados com o fazendeiro. Na correspondência, o ministro anexa uma cópia da carta que José Rodrigues da Cruz Ihe tinha escrito em outubro de 1799, "a qual certamente foi de grande satisfação para sua alteza real, que se dignou mandar remeter". ${ }^{9} \mathrm{~A}$ recomendação expressa é a de que

[...] não só se conceda ao sobredito José Rodrigues da Cruz o que n'ela pede, mas também que auxiliem e promovam as suas ideias procurando-se pelos meios que ele propõe o estender-se e adiantar-se a civilização e administração dos índios e a sua conversão às luzes do Evangelho, animando-se igualmente por meio de sesmarias as margens superiores do Rio Paraíba. ${ }^{10}$

Esse fragmento, além de endossar todo o apoio da Coroa luso-brasileira ao trabalho desenvolvido por Rodrigues da Cruz nos sertões fluminenses, alude ainda a diferentes questões que perpassavam os debates da época. O fundamental, como já foi dito, é a colonização e o desenvolvimento da região, que se desdobra em outros tantos em especial para o presente trabalho, e possivelmente para os interesses de Rodrigues da Cruz: a questão indígena e a dinâmica de ocupação territorial no interior da Província do Rio de Janeiro. Esses desdobramentos da expansão das fronteiras muitas vezes se confundem; a questão indígena não vinha atrelada somente à dinâmica de ocupação, mas também às possibilidades de utilização da mão de obra indígena, comum ao longo do período colonial. A combinação entre o acesso a terra e à mão de obra indígena tinha se mostrado eficiente para o desenvolvimento de novas fazendas. ${ }^{11}$

As terras eram, na maior parte das vezes, tidas, entendidas e encaradas pelos grupos colonizadores como uma oferta ampla e livre. O limite dessa oferta era geralmente representado pelos conflitos com os povos nativos. Assim, ele não se dava por um respeito à sua ocupação anterior, mas sim à representação de uma ameaça, ou de um perigo a ser suplantado; buscar a solução para tais conflitos era justamente o objetivo da Coroa no contexto que estamos analisando.

A construção de uma aliança com José Rodrigues da Cruz foi uma solução encontrada pela Coroa para atuar e se fazer representar no interior da capitania fluminense. Podemos afirmar, nesse sentido, que a aliança não foi em vão, muito menos pouco pensada. Foi sim uma opção política e estratégica bastante calculada e articulada, o que nos leva à necessidade de refletir não apenas sobre a figura do fazendeiro, mas também acerca das escolhas assumidas pela Coroa.

Essa análise sobre a ocupação territorial do interior do Rio de Janeiro se debruça, portanto, sobre duas vertentes distintas, que devem ser consideradas para compreender a

\footnotetext{
${ }^{9}$ Aviso do ministro dos negócios ultramarinos D. Rodrigo de Souza Coutinho ao conde vice-rei do estado do Brasil, D. José de Castro, de 7 mar. 1800.

10 Idem.

${ }^{11}$ ALMEIDA. Políticas indígenas..., 2009, pp. 228-57.
} 
construção da aliança que consagrou a construção do aldeamento. Inicialmente temos a Coroa, muitas vezes personificada na figura do ministro Rodrigo de Souza Coutinho, e em outras, no próprio vice-rei que assumia o governo colonial. O governo buscou um aliado que pudesse estar à frente dos projetos que vislumbrava para os sertões. Na sequência, temos ainda a atuação do fazendeiro, seus discursos e seus posicionamentos, a forma como levou adiante o projeto, e os proveitos que poderia tirar da relação constituída.

A aproximação do fazendeiro com a Coroa deve ser entendida em sua própria importância, já que essa relação poderia lhe render interessante retorno, não necessariamente financeiro, mas na forma de prestígio social, o que de fato já vinha acontecendo. Como dito, o fazendeiro Rodrigues da Cruz parece não ter alcançado lucros ou posses em decorrência dessas alianças, mas agregava importância regional, assumindo a responsabilidade sobre um importante ramo da administração colonial, a questão indígena. Alguns documentos apontam para a situação financeira de endividado em que se acharia o fazendeiro, por volta dos primeiros anos do século XIX, o que o teria forçado a vender parte de suas posses para seus dois sócios, um dos quais seu irmão ${ }^{12}$. Ainda assim, o prestígio do fazendeiro é sempre destacado ao se discorrer sobre a história de Valença. Sua atuação era valorizada não apenas pela Coroa, mas pela população local, reconhecimento que se convertia em seu patrimônio imaterial.

O fazendeiro exerceu importância fundamental no processo de desenvolvimento da região, atendendo a uma preocupação que vislumbrava, no espaço dos sertões, as amplas possibilidades de ampliação da empresa colonial. Como já apresentado, os grupos indígenas eram apenas uma das questões que o governo reconhecia na fronteira, demanda que já estava encaminhada. O interesse na navegação do rio, em especial em relação à flutuação de madeiras em jangadas, fora pontuado na primeira carta enviada por Dom Rodrigo de Souza Coutinho. Ainda em seu projeto colonizador, o ministro menciona a existência de um manual, que estaria em fase de tradução e tinha o intuito de ensinar "o método de se poderem fazer navegáveis os rios em que há cachoeiras" ${ }^{13}$, e que tão logo fosse possível seria remetido à Colônia. Aos olhos europeus, sobretudo os de Dom Rodrigo, permeados pela filosofia iluminista de Portugal, a educação era fundamental, sendo encarada como a chave para solucionar a questão indígena, que tanto o afligia e deveria ser lograda pela conversão "ao grêmio da Santa Igreja tantas mil almas pagãs que entregues ao gentilismo vivem embrenhadas nos vastos sertões sem a luz e o conhecimento do verdadeiro Deus". ${ }^{14}$

Como destacado, o ministro tece correspondências paralelas dirigindo-se ao fazendeiro e ao vice-rei, incentivando a todo o momento o diálogo entre esses dois agentes. Não resta dúvida de que o ministro pretendia repassar ao vice-rei a responsabilidade de dialogar com o fazendeiro para que este pudesse representar os

\footnotetext{
${ }^{12}$ Texto de apresentação do Fundo. Arquivo Nacional, Fundo da Fazenda Pau Grande.

${ }^{13}$ Aviso do ministro D. Rodrigo... ao vice-rei, 7 mar. 1800.

${ }^{14}$ Idem.
} 
interesses da Coroa diretamente da Colônia que, a seus olhos, eram os de promover o desenvolvimento do Brasil, buscando a sobrevivência financeira do Império luso-brasileiro.

Em 1801, o fazendeiro volta a escrever para as autoridades portuguesas, enviando novas informações e discutindo a necessidade de promover o aldeamento dos "índios selvagens que infestavam o rio Preto, o Paraíba, o do Peixe e Sacra Família". ${ }^{15} \mathrm{O}$ fazendeiro indica a presença de outros grupos indígenas, quatro tribos com as quais ele já vinha estabelecendo contato, por intermédio de seus respectivos caciques. Revelando forte senso prático, Rodrigues da Cruz solicita que comandantes da vizinhança fossem destacados para colaborar na abertura de caminhos até as aldeias recém-instaladas.

Ainda nos detendo aos pedidos e solicitações realizados por José Rodrigues da Cruz, cabe destacar que o fazendeiro chega a listar os mantimentos necessários para que os índios pudessem se estabelecer. Supunha-se que, uma vez aldeados, iriam cultivar a terra; mas, antes de findo o primeiro ano, quando poderiam colher suas primeiras plantações, seria necessário prover-lhes de suprimentos e equipamentos para o início das atividades (Tabela 1).

Tabela 1: Lista de pedidos de José Rodrigues da Cruz para o governo português.

\begin{tabular}{|c|l|}
\hline Quantidade & \multicolumn{1}{|c|}{ Item } \\
\hline 200 & Anzóis grandes \\
\hline 200 & Anzóis pequenos \\
\hline 20 & Maços de linhas \\
\hline 150 & Mantas ordinárias \\
\hline 200 & Foices grandes \\
\hline 200 & Foices pequenas \\
\hline 200 & Machados \\
\hline 200 & Enxadas \\
\hline 500 & Facas de cabo de peso \\
\hline 06 & Quintais de ferro da Suécia \\
\hline 01 & Quintal de aço \\
\hline 100 & Tesouras sortidas \\
\hline 200 & Chapéus ordinaries \\
\hline 02 & Chapéus melhores (para os caciques) \\
\hline 2000 & Varas de algodão \\
\hline 12 & Maços de miçangas \\
\hline 01 & Barril de pólvora \\
\hline & Chumbo, fumo etc. \\
\hline
\end{tabular}

Fonte: Carta de Ofício de José Rodrigues da Cruz, de 18 abr. 1801 governo português em abril 1801.

Essa aparentemente simples lista de pedidos pode revelar vários aspectos sobre o projeto em pauta, projeto este que de alguma forma uniu os personagens em questão e fundou um projeto de colonização para os grupos indígenas do Médio Vale do Paraíba. Os

\footnotetext{
${ }^{15}$ Carta de Ofício de José Rodrigues da Cruz, de 18 abr. 1801.
} 
itens arrolados são produtos manufaturados que seriam entregues, reafirmando que a relação entre os grupos indígenas e o fazendeiro estava pautada em negociação, na qual aceitavam produtos que lhes seriam úteis em troca de se estabelecer uma relação cotidiana. Destaca-se ainda que foram solicitados instrumentos para viabilizar a produção de alimentos, que poderiam favorecer o processo de sedentarização dos grupos indígenas, pondo fim ao caráter nômade de ocupação que poderia comprometer os interesses dos colonizadores. Pede-se, do mesmo modo, o envio de chapéus e tecido para vestir a população indígena, com o cuidado de conferir destaque aos caciques, que receberiam "chapéus melhores".

A lista de itens arrolados pelo fazendeiro sugere um processo civilizatório baseado nas premissas de cultivar e defender o território ocupado, refletindo sua própria percepção da ocupação da fronteira. A mediação exercida por José Rodrigues da Cruz não se voltava apenas para o ajuntamento de grupos indígenas e para a promoção da catequese, tal como nos moldes adotados nos aldeamentos coloniais: o projeto do fazendeiro expressa um processo de territorialização da fronteira, dentro do qual incluía os grupos indígenas. Para tanto, era necessário criar condições para que esses grupos cultivassem e defendessem aquelas terras, que já se verificavam férteis e que pouco a pouco se revelaram bastante disputadas. Era, portanto, uma forma de garantir a ocupação pelos índios, aldeados, e com isso inseridos no projeto político da Coroa, levado à frente por Dom Rodrigo de Souza Coutinho e José Rodrigues da Cruz.

Note-se que não eram mais necessários, nem foram solicitados, espelhos ou garrafas de aguardente, que na política indigenista antes vigente serviam como atrativo inicial no processo de aproximação. Rodrigues da Cruz finaliza o texto de sua carta reafirmando o interesse em terminar o quanto antes o trabalho com as duas primeiras aldeias, para que se pudessem "domesticar" ainda os índios de outras duas delas.

Em sua resposta, Dom Rodrigo de Souza Coutinho dá continuidade às questões já levantadas, reconhecendo o trabalho desenvolvido com zelo e primor ${ }^{16}$. Enfatiza que estará escrevendo ao vice-rei e ao capitão-general do Estado do Brasil, para que as autoridades na Colônia possam tratar diretamente com o fazendeiro - e/ou com outros que sigam o exemplo de colaboração com a Coroa no aldeamento de índios; assim, juntos, poderão decidir sobre as providências que se devem tomar para o melhor êxito na "civilização" dos índios. Como visto, essa não era a primeira vez que Dom Rodrigo enviava ordens ao vicereinado no Brasil para que apoiasse as iniciativas no Médio Vale do Paraíba fluminense no que fosse necessário.

Na mesma linha, Dom Rodrigo afirma ao fazendeiro que iria expedir uma ordem à Junta da Fazenda, para que ela também viesse a auxiliar, devendo ser responsável pelas

\footnotetext{
${ }^{16}$ Ofício do ministro D. Rodrigo de Souza Coutinho a José Rodrigues da Cruz, de 25 ago. 1801. Há um pequeno desencontro entre as datas informadas: dois documentos aparecem com referências a meses diferentes, mas percebe-se tratar-se do mesmo documento. Ao final, não se pode afirmar se o documento foi redigido em abril ou agosto de 1801, mas de todo modo o mês não influencia a análise.
} 
[...] despesas que forem necessárias para o referido estabelecimento, de modo que nem falte o preciso para a comodidade e bom tratamento dos índios, nem hajam superfluidades desnecessárias para sua conservação; bastando somente o que se julgar suficiente para servir de estímulo a outras d'aquelas nações, que voluntariamente se quiserem vir aldear. ${ }^{17}$

O ministro ressalta a importância do sucesso do projeto, com o bom tratamento dos grupos indígenas, já aldeados, sugerindo que serviria de estímulo para outros grupos, ainda por aldear. Decerto o projeto proposto por Rodrigues da Cruz serviu aos interesses do ministro, que pretendia fazer dele um modelo, um exemplo, cujo sucesso seria fundamental para seu próprio prolongamento e continuidade.

Apenas seis dias após escrever a carta para José Rodrigues da Cruz, Dom Rodrigo publica uma portaria destinada à Junta da Real Fazenda da capitania do Rio de Janeiro ${ }^{18}$, cumprindo o prometido e dando prosseguimento às determinações anunciadas na correspondência anterior. No documento, o ministro português apresenta oficialmente o nome de José Rodrigues da Cruz como pessoa responsável pelo "descobrimento de algumas nações de índios nos sertões d'essa capitania", determinando à Junta que "na parte que lhe tocar haja de concorrer com todas as providências que forem necessárias". ${ }^{19}$ O objetivo da Coroa, na figura do ministro, é de que a Junta "se entenderá com o dito José Rodrigues da Cruz e de acordo com ele mandará fazer as despesas somente que forem de absoluta necessidade para o referido estabelecimento". ${ }^{20}$

Assegurando a continuidade dos investimentos oficiais no aldeamento dos grupos indígenas de Valença, o ministro destina ao vice-rei algumas responsabilidades, a fim de garantir a efetiva colonização dessa região. Percebemos aqui que ao longo da troca de correspondências, o fazendeiro expôs um projeto ao ministro. De certo, esse não foi o único projeto apresentado ao ministro ${ }^{21}$, mas parece ter atendido aos anseios oficiais, uma proposta que privilegiava a colonização efetiva frente à violência, já tantas vezes explorada. A história do Aldeamento de Valença foi curta, se comparada a outras experiências; mais curta ainda foi a participação do fazendeiro, que veio a falecer poucos anos depois; no entanto, essa experiência inicial confere a José Rodrigues da Cruz uma importância ímpar, sendo reconhecido nos anos subsequentes como o "fundador de Valença".

\footnotetext{
${ }^{17}$ Idem.

${ }^{18}$ Portaria do ministro D. Rodrigo de Souza Coutinho para a junta da Real Fazenda da capitania do Rio de Janeiro, de 31 ago.

19 Idem.

${ }^{20}$ Ibidem.

${ }^{21} \mathrm{Em}$ minha tese de doutoramento, discuto o envolvimento de outros agentes, em especial uma questão que envolveu o cartógrafo Couto Reis. MACHADO, M. M. Entre Fronteiras: terras indígenas nos sertões fluminenses (1790-1824). Tese (Doutorado em História) - PPG História, Universidade Federal Fluminense. Niterói, 2010.
} 


\section{O ALDEAMENTO INDÍGENA}

Até o presente momento da análise, o texto destinou especial atenção à aproximação de interesses e projetos que deram origem a já mencionada aliança entre o governo e os particulares, que por sua vez viabilizou a reunião de grupos indígenas em um aldeamento que recebeu o nome de Nossa Senhora da Glória de Valença. As características e especificidades de um aldeamento fundado na passagem do século XVIII para o XIX fizeram com que ficasse conhecido como um aldeamento tardio, trazendo algumas características que o distinguia dos demais aldeamentos fundados por jesuítas no período colonial.

Como já apontado, Dom Rodrigo de Souza Coutinho incentivou o envolvimento do vice-rei no processo de consolidação de alianças e fundação do aldeamento. O processo, entretanto, foi mais demorado do que a princípio se esperava, visto que as determinações originais foram enviadas ao Conde de Resende, mas logo sua gestão deu lugar ao novo vice-rei Dom Fernando José de Portugal e Castro, o Marquês de Aguiar. A nomeação de um novo ocupante para o cargo de vice-rei implicou reiniciar o processo que já se encontrava em andamento. Ao assumir o cargo, o novo vice-rei precisava continuar os trabalhos, lidando ainda com a realidade de um breve retrocesso, uma vez que foi necessário recomeçar a troca de informações, em vista de garantir o apoio e a aliança entre o vicereinado e o trabalho a ser desenvolvido com os grupos indígenas de Valença.

A essa altura, em 1801, aos poucos se consolidava o resultado de ações desenvolvidas em colaboração do governo português com o fazendeiro José Rodrigues da Cruz: o aldeamento indígena de Nossa Senhora da Glória de Valença. Dom Rodrigo de Souza Coutinho pretendia que os trabalhos com os grupos indígenas prosperassem com velocidade, resultando não apenas no aumento da população aldeada, mas ainda de seus territórios, na promoção da agricultura e do comércio em geral.

O novo vice-rei, Marquês de Aguiar, inicia sua atuação em relação à política indigenista para o Vale do Médio Paraíba fluminense por meio de uma portaria, em 21 de novembro de $1801 .^{22}$ No documento, o vice-rei afirma que dará prosseguimento aos trabalhos de seu antecessor, em observância às determinações do príncipe regente. De forma resumida, o marquês anuncia as novas diretrizes para a política a ser desenvolvida com os Coroados, garante que prestará os auxílios que forem necessários, desejando realizar o quanto antes, de acordo com os termos da lei, o reconhecimento das terras a serem destinadas aos aldeados para que possam cultivá-la. A demarcação das terras era uma preocupação central dos envolvidos com o aldeamento e, ao longo dos anos, revelou-se uma questão complicada. Garantir um título de sesmaria, assim como a medição e a

\footnotetext{
${ }^{22}$ Portaria do vice-rei do Estado do Brasil D. Fernando José de Portugal e Castro para José Rodrigues da Cruz, de 21 nov. 1801.
} 
demarcação da área, era almejado por muitos agentes do mundo colonial. O título poderia servir ainda como instrumento de defesa e argumento de autoridade em favor dos que o possuíam. Os indivíduos reunidos no Aldeamento de Nossa Senhora da Glória de Valença receberam em diversos momentos a promessa da concessão do título de sesmaria das terras que ocupavam, mas essa questão acabou sendo imersa em uma série de outras tantas, e infelizmente o que se assistiu foi ao não reconhecimento oficial das terras que os grupos indígenas ocupavam como suas.

Pensando no desenvolvimento do aldeamento e em facilitar o desenvolvimento dos trabalhos já em andamento, o vice-rei nomeia o Capitão de Ordenanças ${ }^{23}$, Inácio de Souza Werneck, para auxiliar na abertura de caminhos para o aldeamento, tal como fora solicitado pelo fazendeiro. Atendendo também ao pedido de auxílio financeiro para a compra de gêneros para o sustento dos grupos indígenas, o vice-rei aprova que os gastos sejam de responsabilidade governamental, requerendo uma prestação de contas a cada três meses à Fazenda Real, assinada pelo fazendeiro e pelo capitão. Com respeito ao desenvolvimento da educação e aos ensinamentos religiosos, o vice-rei compromete-se a enviar missionários tão logo o fazendeiro julgue oportuno.

José Rodrigues da Cruz encaminha mais um documento ao governo, bastante elucidativo e rico em detalhes e informações, mais especificamente ao vice-rei do Estado do Brasil $^{24}$. Rodrigues da Cruz se apresenta e relata seus feitos, já de conhecimento do príncipe regente. Ao estabelecer o diálogo com um novo interlocutor, o fazendeiro descreve, mais uma vez, sua intenção de "promover a civilização do gentio bravo que infestava o sertão do Paraíba com grande dano aos moradores das freguesias Sacra Família, rio Preto e do Peixe, Paraíba e Paraibuna, desde o ano de $1790 "{ }^{25}$

José Rodrigues da Cruz busca legitimidade para seu pedido de auxílio ao vice-rei. A aprovação do príncipe regente ao seu projeto é apresentada como argumento para justificar a importância de sua solicitação. Rodrigues da Cruz relata as dificuldades que vinha enfrentando e a bravura com que adentrava as matas, de forma pioneira, em prol da "civilização" dos grupos indígenas. Deixa claro também que a motivação para o trabalho estava diretamente relacionada ao compromisso assumido com a Coroa:

Em consequência dele, [documento recebido de Portugal que aprovava seu trabalho com os grupos indígenas] atravessou o suplicante, acompanhado de seus escravos, o sertão; procurou as aldeias dos gentios que até ali só tinha

\footnotetext{
${ }^{23}$ O Capitão de Ordenanças era uma patente militar criada por D. João III em 1549, organizada pelo regimento de 1570 e pela provisão de 1574 (para um texto integral a respeito, ver: http://www.arqnet.pt/exercito). Consistia em um cargo de forte caráter local, sem recebimento de soldo; assim, em geral os ocupantes mantinham seus serviços particulares. Conhecidos como paisanos armados, mesmo sem formação específica, eram frequentemente recrutados em missões de caráter militar e em atividades de controle interno. Para mais informações sobre a hierarquia militar portuguesa e a atuação de Corpos de Ordenanças no Brasil colonial, ver: COSTA, Ana P. P. Organização militar, poder de mando e mobilização de escravos armados nas conquistas: a atuação dos Corpos de Ordenanças em Minas colonial. Revista de História Regional, Ponta Grossa, vol. 11, n. 2, 2006, p. 109-62.

${ }^{24}$ Requerimento de José Rodrigues da Cruz ao vice-rei Marquês de Aguiar, [ano presumido 1801].

${ }^{25}$ Idem.
} 
tratado dentro de sua casa; e conhecendo apenas por acenos, [...] persuadiu aos ditos gentios acompanhassem a sua gente pelo sertão até se encontrar com os moradores do rio Preto, capitania de Minas [...]

O suplicante pôde muito a custo, e sacrificando em garantia a sua mulher e filhos, resolver a que os gentios dessem quatro homens para virem a essa cidade [provavelmente o Rio de Janeiro] reconhecer o exmo. vice-rei do Estado antecessor de V. Excia, o que fizeram e foram apresentados [...] acrescentando além d'isso que desde pouco tempo depois tem sofrido uma epidemia de bexigas, de forma que há quatro meses, o suplicante e toda a escravatura da sua fábrica, apenas tem cuidado em tratar de doentes, caçar para lhes dar que comer, tendo já esgotado seus mandiocaes e bananaes, privando-o, até reduzir a sua safra a uma terça parte. ${ }^{26}$

Cabe lembrar que esse era o período imediatamente seguinte à vigência do Diretório Pombalino, uma legislação que valorizava e legitimava a possibilidade de exploração do trabalho indígena. De fato, embora a legislação vinculasse a garantia de pagamento pelos trabalhos realizados, isso nem sempre ocorreu: a exploração da mão de obra indígena escrava muitas vezes se tornou uma cruel realidade. Diante disso, pode-se supor, como o fez Almeida ${ }^{27}$, que José Rodrigues da Cruz não estivesse somente "amansando e civilizando" os grupos indígenas para garantir a concessão de sesmarias, mas também buscando meios para que esses indivíduos pudessem servir de mão de obra no interior das propriedades que estavam surgindo. O controle sobre a mão de obra indígena justifica o prestígio do fazendeiro em sua região: ele estaria também administrando esses grupos e viabilizando sua prestação de serviços no interior das fazendas. $^{28}$

Em abril de 1802, José Rodrigues da Cruz volta a escrever ao vice-rei Marquês de Aguiar ${ }^{29}$. O assunto, é claro, é o aldeamento e a "civilização" dos "índios selvagens que infestavam o rio Paraíba" ${ }^{30}$; o fazendeiro solicita novamente a ajuda do governo com despesas referentes ao aldeamento. A preocupação, dessa vez, é com o sustento de trabalhadores que deverão abrir caminhos por dentro dos sertões, sem os quais o fazendeiro afirma ser impossível continuar o empreendimento. Rodrigues da Cruz afirma possuir uma quantia em dinheiro para a abertura do caminho, mas que ainda não é suficiente. Além disso, que vem investindo recursos próprios no projeto, mas que acredita serem essas as responsabilidades da Real Fazenda.

\footnotetext{
${ }^{26}$ Requerimento de José Rodrigues da Cruz ao vice-rei Marquês de Aguiar, [ano presumido 1801].

${ }^{27}$ ALMEIDA. Metamorfoses indígenas..., 2003.

${ }^{28}$ Para Stuart Schwartz, a escravidão dos negros vindos da África muitas vezes ocorreu diante do esgotamento das possibilidades de exploração da mão de obra indígena; em seu estudo da região da Bahia, salienta que, nos primórdios, a economia escravista foi fortemente marcada pela exploração do trabalho indígena; esta durou pouco tempo sob a perspectiva legal, mas nos períodos seguintes lançou-se mão de variadas formas de coerção do trabalho indígena. SCHWARTZ, Stuart B. Segredos internos: engenhos e escravos na sociedade colonial; 1550-1835. 3. reimp. São Paulo: Companhia das Letras, 2008 especialmente, o capítulo "Uma geração exaurida”, p. 40-56.

${ }^{29}$ Requerimento de José Rodrigues da Cruz ao vice-rei Marquês de Aguiar, de 12 abr. 1802.

${ }^{30}$ Idem.
} 
Embora o fazendeiro estivesse solicitando ajuda da Real Fazenda, e de fato estivesse enfrentando dificuldades financeiras, a documentação analisada não reflete o uso dessas dificuldades como argumento para solicitar auxílio financeiro ao governo ${ }^{31}$. Apenas reiterava o que sempre afirmava, ou seja, que os custos deveriam ser de responsabilidade da Coroa.

Em 1803, quando a aldeia já era reconhecida pública e oficialmente como Aldeamento de Nossa Senhora da Glória de Valença, José Rodrigues da Cruz dirige-se ao vice-rei Marquês de Aguiar em duas situações ${ }^{32}$. Na primeira, uma carta de ofício datada de 23 de março de 1803 informa com entusiasmo a chegada de mais grupos indígenas ao aldeamento por ele administrado ${ }^{33}$. Volta a mencionar a necessidade da abertura de novas picadas nos matos, realizadas pelos próprios grupos indígenas em conjunto com o capitão Henrique Louzada Magalhães. O segundo documento, um requerimento, é enviado apenas dois meses depois, em 05 de maio de $1803^{34}$.

Rodrigues da Cruz prosseguia trabalhando e prestando contas de seus feitos para as instâncias governamentais. Anunciava novos contatos com grupos indígenas o que, a seus olhos, refletia a promessa de novos aldeamentos ao longo do Vale do Paraíba. Continuava a aldear indivíduos, mas ressaltava a sobrecarga de trabalho que acumulava: vinha se dividindo entre os trabalhos com os grupos nativos, que demandavam idas frequentes ao sertão e à cidade do Rio de Janeiro, e as responsabilidades com a fazenda do Pau-Grande e seus familiares. Dizia acreditar, no entanto, que tal situação iria se acalmar rapidamente, com a esperada chegada do capelão nomeado, Padre Manoel Gomes Leal. De acordo com os relatos de Monsenhor Pizarro ${ }^{35}$, em suas Memórias históricas do Rio de Janeiro, o capelão foi nomeado pela Portaria de 05 de fevereiro de 1803, informando que o padre designado já acumulava experiências com aldeamentos indígenas e em expedições no interior, tendo "feito ali serviços muito úteis à Igreja, e ao Estado".

O fazendeiro mostra-se ainda bastante motivado com a chegada e com o estabelecimento de novos sesmeiros nas terras marginais do rio Paraíba. Eles seriam fundamentais para dar continuidade ao modelo de ocupação que o governo planejava para o interior fluminense, ampliando a fronteira. Seriam, certamente, novos grupos a compor a rede de relações mediadas por José Rodrigues da Cruz, em mais uma etapa desse projeto de colonização e dos grupos indígenas, e das áreas por eles ocupadas. Segundo o fazendeiro, esses sesmeiros estariam apenas aguardando a finalização do trabalho com os grupos indígenas para se estabelecerem na região:

\footnotetext{
${ }^{31}$ Tinha inclusive, de acordo com o texto de apresentação do Fundo da Fazenda Pau Grande do Arquivo Nacional, vendido uma terça parte da fazenda a um irmão e a um sócio, a fim de saldar dívidas.

${ }^{32}$ Carta de Ofício de José Rodrigues da Cruz ao vice-rei do Estado do Brasil D. Fernando José de Portugal, de 23 mar. 1803; e Requerimento de José Rodrigues da Cruz ao vice-rei Marquês de Aguiar, de 5 maio 1803.

${ }^{33}$ Carta de Ofício de José Rodrigues da Cruz ao vice-rei..., 23 mar. 1803.

${ }^{34}$ Requerimento de José Rodrigues da Cruz ao vice-rei Marquês de Aguiar, 5 maio 1803.

${ }^{35}$ ARAÚJO, José de S. A. Pizarro (Monsenhor Pizarro). Memórias históricas do Rio de Janeiro e das províncias anexadas à jurisdição do Vice-Rei do Estado do Brasil [1820]. 5 v. Rio de Janeiro: Ministério da Educação e Saúde; Instituto Nacional do Livro, 1945. vol. 5, p. 253-7.
} 
Feito isso, eu terei a satisfação, no tempo de V. Exa., debaixo de seus auspícios, de ver sossegados de uma vez os povos das freguesias do Alferes, Sacra Família e Paraíba, que muitos anos, apesar de um destacamento que os antecessores de V. Exa. ali entretiveram com as armas na mão, além de muitas fazendas no rio do Peixe, na capitania de Minas, que depois de povoadas foram desamparadas, as quaes já hoje se acham também com os seus colonos trabalhando em sossego. ${ }^{36}$

José Rodrigues da Cruz age com o intuito de promover uma colheita de sucesso no interior do aldeamento, requerendo para tal a parceria com o governo, a fim de garantir que tudo que fora realizado até então pudesse estar refletido na prosperidade da lavoura. O trabalho, dizia, encontrava-se em estágio adiantado e o status de aldeamento podia ser assegurado pela presença do capelão, responsável pela administração religiosa, Manoel Gomes Leal.

É evidente que o fazendeiro vinha recebendo da Corte, por intermédio de seus representantes no Rio de Janeiro, apoio para seu trabalho com os grupos indígenas, assegurando para si o importante papel de mediador das relações no interior daquela comunidade. Pode-se questionar quais os reais benefícios de tal aproximação com a Coroa, se de fato se fizeram sentir na vida de José Rodrigues da Cruz, já que sua saúde financeira não parecia ser das melhores. Entretanto, há que se perceber que a questão financeira e as posses materiais poderiam não ser seu objetivo central. Como sugere Levi acerca de um tabelião do Piemonte no século XVII, é possível que, para o fazendeiro, não interessassem diretamente bens móveis ou imóveis, mas o prestígio das relações ${ }^{37}$. Essa seria uma riqueza bem mais rara, construída ao longo de muitos anos de trabalho na administração de negociações e conflitos, em um envolvimento íntimo com todas as questões internas dessa sociedade localizada em uma fronteira fluminense.

É notório o envolvimento da Coroa com o processo de aldeamento indígena e com o estabelecimento de alianças em prol do desenvolvimento dos sertões. O discurso oficial salientava sempre a necessidade de apaziguar a região e possibilitar a expansão da fronteira territorial. O projeto estava garantindo a ocupação do território, sustentado por construção de alianças e negociações, evidenciando o interesse maior em garantir a sobrevivência dos grupos indígenas e o bom relacionamento entre os grupos envolvidos. Um projeto que parece ter sido bem aceito pelas autoridades do governo, que depositaram sua confiança e seus investimentos, financeiros ou não, assegurando a José Rodrigues da Cruz a responsabilidade de mediar as relações daquela sociedade.

Além da ajuda financeira, da concessão de terras e da confiança depositada, a partir de 1803, o aldeamento já contava com assistência religiosa, na figura do padre Manoel Gomes Leal. Diferentemente do papel central de liderança e administração exercido pelos jesuítas nos aldeamentos dos anos coloniais, nesse contexto o padre seria apenas mais um dos agentes autorizados dentro do aldeamento, responsável por colaborar

\footnotetext{
${ }^{36}$ Carta de Ofício de José Rodrigues da Cruz ao vice-rei..., 23 mar. 1803.

${ }^{37}$ LEVI, Giovanni. A herança imaterial: trajetória de um exorcista no Piemonte do século XVII. Rio de Janeiro: Civilização Brasileira, 2000.
} 
na "civilização" dos grupos indígenas pela catequese. Certamente um objetivo seguinte seria a construção de uma igreja, tarefa que logo lhe foi destinada pelo bispo José Joaquim Justiniano, ao incumbi-lo de

[...] construir, edificar, ou levantar altar em sítio conveniente, benzer a Capela, ou Igreja, que erigisse, precedendo-lhe faculdade régia para administrar todos os sacramentos aos índios, sem exceção do de matrimônio, e finalmente de construir, e benzer cemitério. ${ }^{38}$

O Padre Manoel Gomes Leal obteve sucesso no pedido de licença e nos anos seguintes direcionou seus esforços na tentativa de concretizar a construção da Igreja de Nossa Senhora da Guia de Valença. Isso não foi rapidamente alcançado, nem tão apoiado como esperava o capelão; a aldeia ainda enfrentaria disputas pela garantia das terras onde seria realizada a obra e por fim não podemos afirmar que se alcançou sucesso.

Durante os primeiros anos de sua existência, o aldeamento de Nossa Senhora da Glória de Valença obteve um relativo sucesso, em consonância com as expectativas de parte dos agentes envolvidos, os particulares e o governo, agora se inserindo a figura do capelão representando a Igreja Católica. Os grupos indígenas vinham sendo reunidos, a região era paulatinamente pacificada, permitindo a incipiente colonização das terras até então ocupadas pelos grupos indígenas. Tal sucesso estava diretamente atrelado à convergência de interesses que possibilitou aliança entre as partes envolvidas. José Rodrigues da Cruz pôde contar com o apoio financeiro e técnico fornecido pela Coroa durante todo o período. O sucesso esperado se refletia ainda nas alianças construídas com os grupos indígenas e na relação de confiança, uma fronteira de interesses estabelecida entre colonizadores e aldeados. O aldeamento era um empreendimento fundamental no processo de conquista dos sertões fluminenses, garantindo as condições necessárias de segurança frente aos povos indígenas para que as novas sesmarias fossem paulatinamente ocupadas e a região assumisse os contornos desejados pela Coroa luso-brasileira.

\section{CONSIDERAÇÕES FINAIS}

Ao longo das páginas deste artigo, procurou-se reconstruir uma parte da dinâmica dos movimentos nas fronteiras do Rio de Janeiro na passagem do século XVIII para o século XIX, tendo por base a região do Médio Vale do Paraíba, com especial atenção para o Aldeamento de Nossa Senhora da Glória de Valença e para o projeto de colonização do qual ele se originou. Um exemplo que envolveu os mais variados agentes, cada qual imbuído de seus respectivos e distintos interesses. Grupos indígenas, padres, fazendeiros, sesmeiros, moradores e agentes da Coroa. Indivíduos que conviveram nesse espaço móvel, encontrando e desencontrando interesses, atuando em prol de seus próprios objetivos.

\footnotetext{
${ }^{38}$ ARAÚJO (Monsenhor Pizarro). Memórias históricas... 5.v., 1945, p. 255.
} 
Consideramos, pois, que foi fundamental a aliança entre os grupos colonizadores para que o projeto do aldeamento pudesse se concretizar. Reconhecemos ainda as particularidades de um projeto que envolvia interesses de sedentarização e colonização dos grupos indígenas envolvidos, possibilitando a abertura da fronteira para a ocupação das terras por colonos, tal como se assistiu nos anos subsequentes. 